\title{
Application of a physiologically based pharmacokinetic model for the evaluation of single-point plasma phenotyping method of CYP2D6
}

DOI:

10.1016/j.ejps.2016.07.001

\section{Document Version}

Accepted author manuscript

Link to publication record in Manchester Research Explorer

Citation for published version (APA):

Chen, R., Rostami-Hodjegan, A., Wang, H., Berk, D., Shi, J., \& Hu, P. (2016). Application of a physiologically based pharmacokinetic model for the evaluation of single-point plasma phenotyping method of CYP2D6. European Journal of Pharmaceutical Sciences, 92, 131-136. https://doi.org/10.1016/j.ejps.2016.07.001

\section{Published in:}

European Journal of Pharmaceutical Sciences

\section{Citing this paper}

Please note that where the full-text provided on Manchester Research Explorer is the Author Accepted Manuscript or Proof version this may differ from the final Published version. If citing, it is advised that you check and use the publisher's definitive version.

\section{General rights}

Copyright and moral rights for the publications made accessible in the Research Explorer are retained by the authors and/or other copyright owners and it is a condition of accessing publications that users recognise and abide by the legal requirements associated with these rights.

\section{Takedown policy}

If you believe that this document breaches copyright please refer to the University of Manchester's Takedown Procedures [http://man.ac.uk/04Y6Bo] or contact uml.scholarlycommunications@manchester.ac.uk providing relevant details, so we can investigate your claim.

\section{OPEN ACCESS}




\section{Accepted Manuscript}

Application of a physiologically based pharmacokinetic model for the evaluation of single-point plasma phenotyping method of CYP2D6

Rui Chen, Amin Rostami-Hodjegan, Haotian Wang, David Berk, Jun Shi, Pei Hu

PII: $\quad$ S0928-0987(16)30241-X

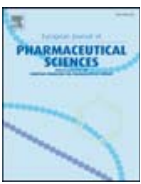

DOI: $\quad$ doi: $10.1016 /$ j.ejps.2016.07.001

Reference: $\quad$ PHASCI 3624

To appear in:

Received date: 17 December 2015

Revised date: $\quad 1$ July 2016

Accepted date: 1 July 2016

Please cite this article as: Chen, Rui, Rostami-Hodjegan, Amin, Wang, Haotian, Berk, David, Shi, Jun, Hu, Pei, Application of a physiologically based pharmacokinetic model for the evaluation of single-point plasma phenotyping method of CYP2D6, (2016), doi: 10.1016/j.ejps.2016.07.001

This is a PDF file of an unedited manuscript that has been accepted for publication. As a service to our customers we are providing this early version of the manuscript. The manuscript will undergo copyediting, typesetting, and review of the resulting proof before it is published in its final form. Please note that during the production process errors may be discovered which could affect the content, and all legal disclaimers that apply to the journal pertain. 


\section{Application of a physiologically based pharmacokinetic model for the evaluation of single-point plasma phenotyping method of CYP2D6}

Rui Chen, M.D. ${ }^{1}$, Amin Rostami-Hodjegan, Ph.D. ${ }^{2,3}$, Haotian Wang, M.D. ${ }^{4}$, David Berk, Ph.D. ${ }^{2}$, Jun Shi, M.D., Ph.D. ${ }^{5}$, Pei Hu, M.D., Ph.D. ${ }^{1}$

1 Clinical Pharmacology Research Center, Peking Union Medical College Hospital, Beijing, China.

2 Manchester Pharmacy School, University of Manchester, Manchester, UK. 3 Simcyp Limited (a Certara Company), Blades Enterprise Centre, Sheffield, UK

4 Cardiology Department, Beijing Tsinghua Chang Gung Hospital, Beijing, China.

5 Roche Innovation Center Shanghai, Shanghai, China.

Correspondence to: Pei Hu, email: peihu_pumc@126.com 


\section{Application of a physiologically based pharmacokinetic model for the evaluation of single-point plasma phenotyping method of CYP2D6}

Rui Chen, M.D. ${ }^{1}$, Amin Rostami-Hodjegan, Ph.D. ${ }^{2,3}$, Haotian Wang, M.D. ${ }^{4}$, David Berk, Ph.D. ${ }^{2}$, Jun Shi, M.D., Ph.D. ${ }^{5}$, Pei Hu, M.D., Ph.D. ${ }^{1}$

1 Clinical Pharmacology Research Center, Peking Union Medical College Hospital, Beijing, China.

2 Manchester Pharmacy School, University of Manchester, Manchester, UK.

3 Simcyp Limited (a Certara Company), Blades Enterprise Centre, Sheffield, UK

4 Cardiology Department, Beijing Tsinghua Chang Gung Hospital, Beijing, China.

5 Roche Innovation Center Shanghai, Shanghai, China.

\section{Abstract}

Purpose

Determining metabolic ratio from single-point plasma is potentially a good phenotyping method of CYP2D6 to reduce the required time interval and increase the reliability of data. It is difficult to conduct large sample size clinical trials to evaluate this phenotyping method for multiple plasma points. A physiologically based pharmacokinetic (PBPK) model can be developed to do simulations based on the large virtual Chinese population and evaluate single-point plasma phenotyping method of CYP2D6.

\section{Methods}

Pharmacokinetic data of dextromethorphan (DM) and its metabolite dextrorphan (DX) after oral administration were used for model development. The SimCYP ${ }^{\circledR}$ model incorporating Chinese demographic, physiological, and enzyme data was used to simulate DM and DX pharmacokinetics in different phenotype groups.

Results 
The ratios of the simulated to the observed mean $A \cup C$ and $C_{\max }$ of $D M$ were 1.01 and 0.81 for extensive metabolizers (EMs), 0.90 and 0.81 for intermediate metabolizers (IMs), and 1.12 and 0.84 for poor metabolizers (PMs). The ratios of the simulated to the observed mean $A U C$ and $C_{\max }$ of DX were 1.12 and 0.89 for EMs, 0.66 and 0.62 for IMs. All ratios were within the predefined criterion of $0.5-2$. The simulations of DM and DX pharmacokinetic profiles in 1000 virtual Chinese subjects with reported frequencies of different phenotypes indicated that statistically significant correlations were found between metabolic ratio of $D M$ to $D X\left(M R_{D M} / D X\right)$ from $A U C$ and from single-point plasma from 1 to $30 \mathrm{~h}$ (all $\mathrm{p}$-values $<0.001$ ).

\section{Conclusion}

$M R_{D M / D x}$ from single-point plasma from 1 to $30 \mathrm{~h}$ after the administration of $30 \mathrm{mg}$ controlled-release DM could predict the $M R_{D M / D x}$ from AUC well and could be used as the phenotyping method of CYP2D6 for EMs, IMs, and PMs.

Key words: CYP2D6, phenotyping method, physiologically based pharmacokinetic model, virtual population.

\section{Introduction}

Cytochrome P450 2D6 (CYP2D6) is one of the most widely investigated polymorphic enzymes owing to its wide inter-individual and inter-ethnic variability. So far, more than 100 allelic variants have been identified (http://www.cypalleles.ki.se/). Phenotypes are stratified and include poor (PM), intermediate (IM), extensive (EM), and ultra-rapid (UM) metabolizer phenotypes. ${ }^{[1]}$ Differing enzyme activities can result in dose-dependent adverse events or therapeutic failures after administration of CYP2D6 substrates. ${ }^{[2]}$ For instance, CYP2D6 polymorphism affects the clinical outcome of psychoactive drugs. The meta-analysis by Kirchheineret al ${ }^{[19]}$ reveals that the dosage of about $50 \%$ of the commonly used antipsychotics is dependent on the CYP2D6 phenotype. 
It is convenient to test genotypes clinically. But given the large number of allelic variants and the presence of structural and copy number variability, it is a challenge to determine the genotype of CYP2D6. Besides, there is big uncertainty in the prediction of the large-scale enzyme activities from genotypes of CYP2D6, given the number of allelic variants and resulting complexity of allele combinations. ${ }^{[1,2]}$ Measured phenotypes should provide the most reliable data for enzyme activities. Determining the phenotype of CYP2D6 before administration of substrates with narrow therapeutic index will be beneficial for dose adjustment while cost, time and clinical convenience are considered. Debrisoquine and dextromethorphan (DM) were suggested as the best CYP2D6 phenotyping drugs, with debrisoquine having the problem of very limited availability as a therapeutic drug. ${ }^{[22]}$ So dextromethorphan was currently the most preferred probe drug for CYP2D6 metabolic activity

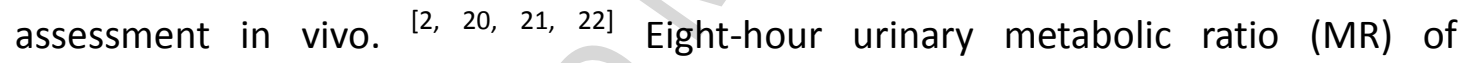
dextromethorphan to dextrorphan (DX) is widely used to differentiate between EM and PM. However urine collection for 8 hours could be demanding and especially inconvenient for outpatients. Therefore alternative procedures have been developed for easier and quicker phenotyping. Phenotyping method based on single-point plasma sample has been developed. ${ }^{[3,4]}$ Metabolic ratio of $\mathrm{DM}$ to $\mathrm{DX}\left(\mathrm{MR}_{\mathrm{DM} / \mathrm{DX}}\right)$ measured in one plasma sample ( $3 \mathrm{~h}$ post-dose) indicated tight correlation with $M R_{D M / D x}$ measured in urine (0-4 $\mathrm{h}$ post-dose) in 95 healthy Caucasian subjects including EMs and PMs. ${ }^{[4]} \mathrm{Hu}$ et al. ${ }^{[3]}$ suggested $\mathrm{MR}_{\mathrm{DM} / \mathrm{DX}}$ measured in single-point plasma (at any point between 1 to $5 \mathrm{~h}$ or at $8 \mathrm{~h}$ ) was feasible for determining the phenotype of CYP2D6 in EMs and IMs base on data from 12 healthy Chinese subjects. [3]

Determining $M R_{D M / D x}$ from single-point plasma is potentially a good way to reduce the required time interval and increase the reliability of data. Clinical studies are typically designed to evaluate the plasma phenotyping methods, such as Hu's study. ${ }^{[3]}$ But it is difficult to conduct large sample size clinical trials to assess the phenotyping method for multiple plasma points, given that many blood samples are 
taken from each subject. Therefore the sample size is quite small when multiple plasma points are targeted. It is well known that data from small trials can't describe the inter-individual variability or the polymorphism-associated effects on pharmacokinetics well, given the wide range of CYP2D6 activities resulting from the allelic diversity. Moreover, it is hard to include subjects with all phenotypes in a small trial, in light of the low frequency of IMs in Caucasian and low frequency of PMs in Asian. The results obtained in EMs and IMs ${ }^{[3]}$ couldn't be extrapolated to PMs. These shortcomings result in the limited value of evaluating plasma phenotyping methods in small clinical trials. A physiologically based pharmacokinetic (PBPK) model can be developed to do simulations based on the large virtual Chinese population and include subjects with more phenotypes.

In the present study, a dynamic PBPK model was developed for DM and its active metabolite DX in three CYP2D6 phenotype groups (EM, IM, and PM). A virtual Chinese population consisting of EM, IM, and PM subjects with the reported frequencies was developed to simulate the pharmacokinetic profiles of DM and DX in a large Chinese population. The simulated data could then be used to evaluate the alternative phenotyping methods of CYP2D6 in Chinese population.

\section{Methods}

\section{General}

SimCYP Population-based simulator, version 13.0 (SimCYP Ltd, Sheffield, UK) was used to simulate the time courses of DM and DX concentrations in plasma. The DM model file and virtual healthy Chinese population as provided in the software were used. Dextrorphan model file was defined based on literature data.

\section{Model development}

The input parameters for the DM model are summarized in Table 1. The DM model 
used the advanced dissolution, absorption and metabolism (ADAM) model for absorption. ${ }^{[5]}$ A default minimal PBPK model was applied for distribution. The minimal PBPK model could be described as a "lumped" PBPK model which, in its simplest form, has only four compartments, predicting only the systemic, portal vein and liver concentrations. The default value of volume of distribution at steady state $\left(\mathrm{V}_{\text {ss }}\right)$ for DM model in SimCYP was $14.3 \mathrm{~L} / \mathrm{kg}$ and was reset to $16.0 \mathrm{~L} / \mathrm{kg} .{ }^{\left[{ }^{6]}\right.}$ CYP3A4-, 2B6-, 2C9-, 2C18-, and 2C19-mediated intrinsic clearance values $\left(\mathrm{CL}_{\text {int,3A4}}, \mathrm{CL}_{\text {int,2B6}}\right.$, $\mathrm{CL}_{\text {int, } 2 C 9}, \mathrm{CL}_{\text {int, } 2 \mathrm{C18}}$, and $\mathrm{CL}_{\text {int,2C19}}$ ) were the default values in $\mathrm{DM}$ file in SimCYP library. CYP2D6-mediated intrinsic clearance $\left(\mathrm{CL}_{\text {int,2D6 }}\right)$ was estimated in SimCYP by simultaneously fitting the observed mean plasma concentration-time profiles extracted from previous publications ${ }^{[7]}$ for PM subjects and from unpublished data for EM and IM subjects, respectively. The objective function was Weighted Least Square and it was weighted by reciprocal of predicted squared. The pharmacokinetic data of DM in Chinese EM and IM subjects were obtained after administration of controlled-release (CR) DM tablet, which contained controlled-release pellets. However, the release profile of the tablet hasn't been reported. The release profile of DM was estimated by fitting the observed plasma concentration-time profiles in SimCYP in EM and IM subjects. All parameters except $\mathrm{CL}_{\text {int,2D6 }}$ were identical across the three phenotype subjects.

The DM model was evaluated in virtual Chinese EM and IM subjects and was compared to unpublished clinical data. No pharmacokinetic profiles of DM in Chinese PMs have been reported. The reported pharmacokinetic profiles of DM in Caucasian PMs were used instead. Some ethnicity dependent factors, e.g. diet, can affect the exposures of drugs. Therefore, AUC values of DM between Caucasian EMs ${ }^{[7,11,17,18]}$ and Chinese EMs were compared to assess the ethnicity-dependent difference. A predefined twofold deviation boundary - a measure commonly used by others ${ }^{[8-10]}$ was used to evaluate the difference, which was to say a twofold deviation was allowed. PK profiles of DM in Caucasian PMs would be corrected by a correction coefficient only if the deviation between Caucasian EMs and Chinese EMs was larger 
than twofold. The correction coefficient was calculated by comparison of AUC values of DM between Caucasians and Chinese. If the deviation was within twofold, no data correction would be performed. The deviation between Chinese EMs and Caucasian EMs was 1.25-fold and thus data correction was deemed unnecessary. The observed concentration-time profile of DM in Caucasian PMs was used directly to substitute for that in Chinese PMs.

Table 1 Parameter values used for the dextromethorphan simulations

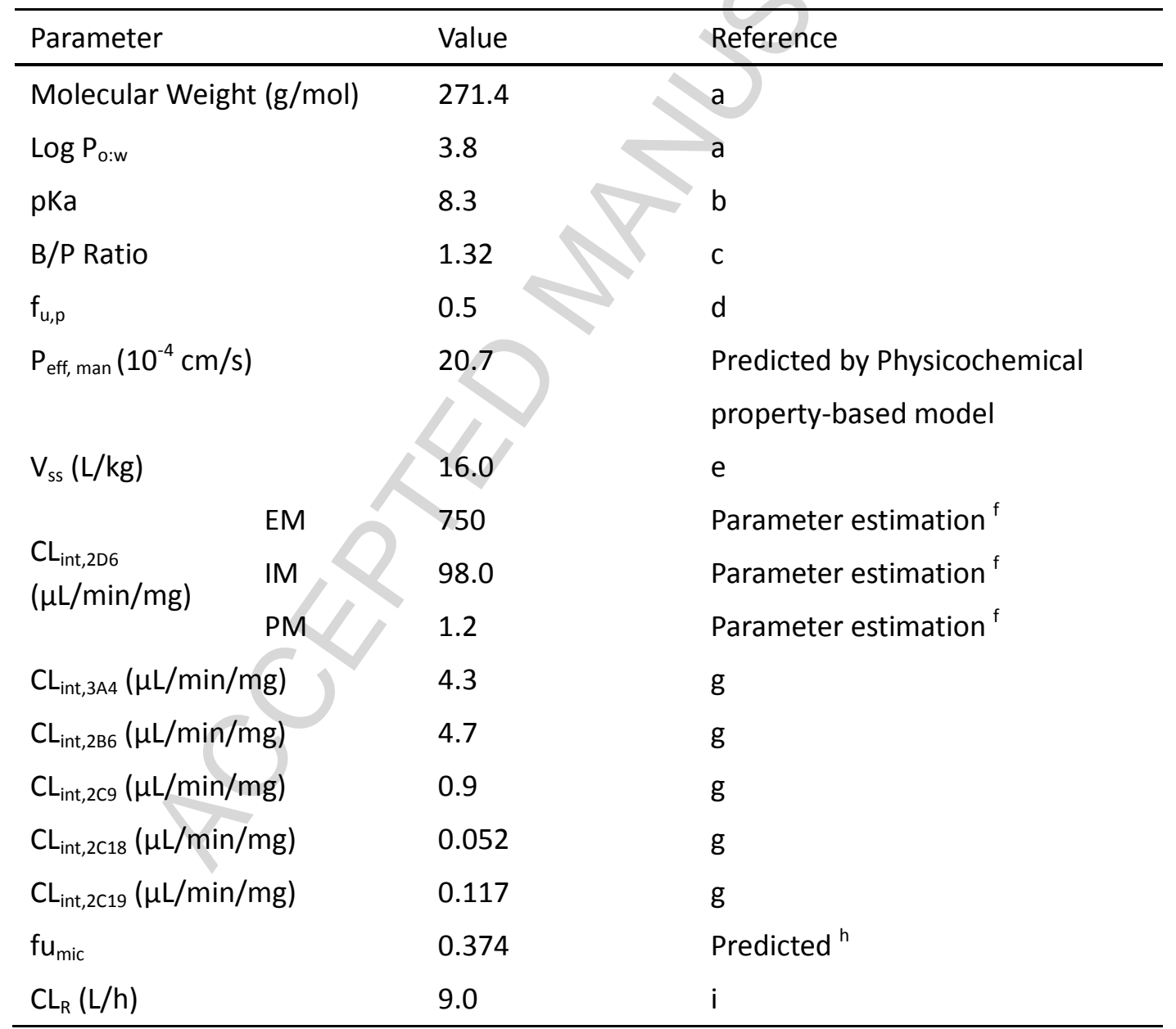

a. http://www.drugbank.ca/

b. Reported (Dollery, 1992). ${ }^{[23]}$

c. Pfizer in-house data.

d. Reported (Capon et al., 1996). ${ }^{[7]}$

e. Reported (Moghadamnia et al., 2003). ${ }^{[6]}$

f. $\mathrm{CL}_{\text {int,2D6 }}$ was estimated in SimCYP by simultaneously fitting observed concentration-time profiles of dextromethorphan extracted from unpublished data of EM and IM subjects, and from previously reported data of PM subjects (Capon et al., 1996). ${ }^{\text {[7] }}$

g. Scaled up from reported $V_{\max }$ and $K_{m}$ (Yu and Haining, 2001) ${ }^{[24]}$ using the abundance and inter system extrapolation factor (ISEF) values in SimCYP version 13.0. 
h. Predicted by the prediction toolbox in SimCYP.

i. Reported median $\mathrm{CL}_{\mathrm{R}}$ of dextromethorphan: $9.0 \mathrm{~L} / \mathrm{h}$ (Capon et al., 1996). ${ }^{[7]}$

Input parameters for DX were obtained from the literature (Table 2). For distribution, a minimal PBPK model with one compartment was applied. The $\mathrm{V}_{s s}$ was the calculated mean value of reported distribution volumes of DM in literature. ${ }^{[12,13]}$ The $\mathrm{CL}_{\text {int,3A4 }}$ was estimated in SimCYP by fitting observed plasma concentration-time profiles from unpublished data. All parameters of DX were identical across the three phenotype populations.

Table 2 Parameter values used for the dextrorphan simulations

\begin{tabular}{|c|c|c|}
\hline Parameter & Value & Reference \\
\hline Molecular Weight (g/mol) & 257.4 & a \\
\hline $\log P_{o: w}$ & 3.46 & a \\
\hline pKa & & $\mathrm{a}$ \\
\hline B/P Ratio & & $\mathrm{b}$ \\
\hline$f_{u, p}$ & 0.55 & $\mathrm{C}$ \\
\hline $\mathrm{V}_{\mathrm{ss}}(\mathrm{L} / \mathrm{kg})$ & 6.78 & $d$ \\
\hline $\mathrm{CL}_{\text {int }, 3 \mathrm{~A} 4}(\mu \mathrm{L} / \mathrm{min} / \mathrm{mg})$ & 2.4 & Parameter estimation ${ }^{\mathrm{e}}$ \\
\hline$f u_{\text {mic }}$ & 0.5 & Predicted $^{f}$ \\
\hline $\mathrm{CL}_{\mathrm{R}}(\mathrm{L} / \mathrm{h})$ & 5 & g \\
\hline & \multicolumn{2}{|c|}{ b. Assumed (Ke et al., 2013). ${ }^{[13]}$} \\
\hline \multicolumn{3}{|c|}{ c. Reported (Lutz and Isoherranen, 2011). ${ }^{[14]}$} \\
\hline \multicolumn{3}{|c|}{ d. Calculated mean value of reported $V_{d}$ in literature (Albers et al., 1995; Ke et al., 2013). ${ }^{[12,13]}$} \\
\hline \multicolumn{3}{|c|}{$\begin{array}{l}\text { e. } \mathrm{CL}_{\text {int, } 3 \mathrm{~A} 4} \text { was estimated in SimCYP by simultaneously fitting observed concentration-time profiles of } \\
\text { dextrorphan extracted from unpublished data of EM and IM subjects. }\end{array}$} \\
\hline \multicolumn{3}{|c|}{ f. Predicted by the prediction toolbox in SimCYP. } \\
\hline \multicolumn{3}{|l|}{ g. Optimized (Ke et al., 2013). ${ }^{[13]}$} \\
\hline
\end{tabular}

\section{Simulation}

Simulations were based on virtual Chinese healthy populations by matching distributions of age and sex to the actual study data (age from 27 to $37 \mathrm{y}$, all male). Input parameters from Tables $\mathbf{1}$ and $\mathbf{2}$ were used to simulate the plasma 
concentration-time profiles of DM and DX. The enzyme abundance of CYP2D6 was set to be $5.5 \mathrm{pmol} / \mathrm{mg}$-protein, which was the default value of EM in SimCYP library for all phenotype groups. In another word, the enzyme abundance of CYP2D6 was assumed to be the same for all phenotypes, and the enzyme activity of CYP2D6 was different for different phenotypes, to simplify the model. The plasma concentration-time profiles of DM and DX were simulated in EM, IM, and PM populations, respectively, based on the different $\mathrm{CL}_{\text {int }}$ values estimated previously.

The comparisons of observed and predicted plasma concentration profiles of DM and DX following a single oral dose of $30 \mathrm{mg}$ CR DM to eleven EM subjects of CYP2D6 and ten IM subjects of CYP2D6 aged 27 to 37 years (unpublished data) were performed. The same comparison following a single oral dose of $30 \mathrm{mg}$ DM to ten PM subjects of CYP2D6 aged 20 to 40 years was performed. Ten trial simulations were performed for each phenotype group.

The metric for assessing predictive performance of the PBPK model of DM and DX was the ratio of the predicted to the observed mean exposure, with the exposure defined as $\mathrm{C}_{\max }$ or AUC. Two thresholds of 0.8-1.25 and 0.5-2 were predefined for both $\mathrm{C}_{\max }$ and AUC. ${ }^{[15]}$

\section{Model application}

The calculated frequencies of UM, EM, IM, and PM of CYP2D6 in Chinese population were $1.84 \%, 47.9 \%, 49.3 \%$, and $0.96 \%$, respectively. ${ }^{[16]}$ No pharmacokinetic profiles of DM in UMs have been reported. Therefore the frequency of UMs was assigned to EM groups, given the enzymatic activity of CYP2D6 in UM group is the most close to EM group. The corrected frequencies of EM, IM, and PM of CYP2D6 in Chinese population were $49.7 \%, 49.3 \%$, and $0.96 \%$, respectively. A virtual Chinese population of 1000 subjects with the reported frequencies of the three phenotypes was generated. The virtual Chinese population consisted of 500 male and 500 female subjects, with all subjects aged 20 to 50 years. The simulation followed the dosing regimen of the present clinical trial with $30 \mathrm{mg}$ DM CR tablet. The plasma 
concentration-time profiles of DM and DX were simulated, respectively.

$M R_{D M / D X}$ from $A U C_{0-i n f}$ and from serial plasma points were calculated based on the simulated data. $\mathrm{MR}_{\mathrm{DM} / \mathrm{Dx}}$ from $\mathrm{AUC}_{0 \text {-inf }}$ was taken as gold standard. Spearman's correlation coefficients were calculated to assess the relationship between AUC $\mathrm{MR}_{\mathrm{DM} / \mathrm{DX}}$ and plasma $M R_{\mathrm{DM} / \mathrm{DX}}$, with $\mathrm{p}$-value less than 0.05 regarded as significant.

\section{Results}

\section{Model development}

\section{Simulation of plasma drug concentration-time profiles}

Predicted mean pharmacokinetic parameter values of DM for the ten virtual trials were compared with the corresponding observed mean values in EM, IM, and PM subjects, respectively, as shown in Table 3. Predicted mean pharmacokinetic parameter values of DX for the ten virtual trials were compared with the corresponding observed mean values in EM and IM subjects, respectively, as shown in Table 4. Simulated plasma concentration-time profiles of DM and DX following the single dosing of $30 \mathrm{mg} D M$ were able to recover the observed data in $E M, I M$, and PM subjects, respectively, as shown in Figure 1.

In EMs, the ratios of the simulated to the observed mean AUC and $C_{\max }$ of $D M$ in the entire virtual population were 1.01 and 0.81 , within the predefined criterion of 0.8-1.25. The ratios of the simulated to the observed mean AUC and $C_{\max }$ of DX in the entire virtual population were 1.12 and 0.89 , within the predefined criterion of 0.8-1.25. In IMs, the ratios of the simulated to the observed mean $A U C$ and $C_{\max }$ of DM in the entire virtual population were 0.90 and 0.81 , within the predefined criterion of $0.8-1.25$. The ratios of the simulated to the observed mean AUC and $C_{\max }$ of DX in the entire virtual population were 0.66 and 0.62 . In PMs, the ratios of the simulated to the observed mean $A U C$ and $C_{\max }$ of $D M$ in the entire virtual population were 1.12 and 0.84 , within the predefined criterion of $0.8-1.25$. All ratios of the 
simulated to the observed mean $A U C$ and $C_{\max }$ of $D M$ in the virtual populations were within the predefined criterion of 0.5-2.

Table 4 Observed $^{\mathrm{a}}$ and predicted pharmacokinetic parameter values of dextromethorphan

\begin{tabular}{llll}
\hline Phenotype & Parameter & Predicted $^{b}$ & Observed $^{b}$ \\
\hline EM & $\mathrm{T}_{\max }(\mathrm{h})$ & $5.34(0.38)$ & $4.95(0.27)$ \\
& $\mathrm{C}_{\max }(\mathrm{ng} / \mathrm{mL})$ & $1.01(0.55)$ & $1.25(1.34)$ \\
& $\mathrm{AUC} \mathrm{C}_{0-\text { inf }}(\mathrm{ng} / \mathrm{mL} / \mathrm{h})$ & $13.8(7.93)$ & $13.7(16.30)$ \\
& $\mathrm{CL}(\mathrm{L} / \mathrm{h})$ & $3379(2592)$ & $4487(3337)$ \\
& $\mathrm{T}_{\max }(\mathrm{h})$ & $5.44(0.40)$ & $5.60(1.58)$ \\
$\mathrm{IM}$ & $\mathrm{C}_{\max }(\mathrm{ng} / \mathrm{mL})$ & $6.18(2.54)$ & $7.62(3.01)$ \\
& $\mathrm{AUC} \mathrm{C}_{0-\mathrm{inf}}(\mathrm{ng} / \mathrm{mL} / \mathrm{h})$ & $106(53.1)$ & $117(64.7)$ \\
& $\mathrm{CL}(\mathrm{L} / \mathrm{h})$ & $372(241)$ & $523(791)$ \\
& $\mathrm{T}_{\max }(\mathrm{h})$ & $3.63(0.54)$ & 4 \\
$\mathrm{PM}$ & $\mathrm{C}_{\max }(\mathrm{ng} / \mathrm{mL})$ & $19.6(5.16)$ & 23.4 \\
& $\mathrm{AUC} \mathrm{C}_{0-\mathrm{inf}}(\mathrm{ng} / \mathrm{mL} / \mathrm{h})$ & $579(198)$ & 519 \\
& $\mathrm{CL}(\mathrm{L} / \mathrm{h})$ & $56.7(44.7)$ & 42 \\
\hline
\end{tabular}

a. Observed pharmacokinetic parameter values of dextromethorphan of EM and IM subjects were from unpublished data. Observed pharmacokinetic parameter values of dextromethorphan of PM subjects were from the reported study (Capon et al., 1996). ${ }^{[7]}$

b. Mean(SD)

Table 5 Observed ${ }^{\mathrm{a}}$ and predicted pharmacokinetic parameter values of dextrorphan

\begin{tabular}{llll}
\hline Phenotype & Parameter & Predicted $^{\mathrm{b}}$ & Observed $^{\mathrm{b}}$ \\
\hline $\mathrm{EM}$ & $\mathrm{T}_{\max }(\mathrm{h})$ & $4.79(0.45)$ & $3.95(1.15)$ \\
& $\mathrm{C}_{\max }(\mathrm{ng} / \mathrm{mL})$ & $1.66(0.89)$ & $1.87(0.91)$ \\
& $\mathrm{AUC}_{0-\text { inf }}(\mathrm{ng} / \mathrm{mL} / \mathrm{h})$ & $15.3(7.8)$ & $13.6(5.11)$ \\
$\mathrm{IM}$ & $\mathrm{T}_{\max }(\mathrm{h})$ & $4.91(0.46)$ & $4.40(0.99)$ \\
& $\mathrm{C}_{\max }(\mathrm{ng} / \mathrm{mL})$ & $1.25(0.67)$ & $2.03(0.46)$ \\
& $\mathrm{AUC} C_{0-\text { inf }}(\mathrm{ng} / \mathrm{mL} / \mathrm{h})$ & $14.5(7.71)$ & $22.0(5.31)$ \\
$\mathrm{PM}$ & $\mathrm{T}_{\max }(\mathrm{h})$ & $3.21(0.52)$ & \\
\hline
\end{tabular}




$$
\begin{array}{ll}
\mathrm{C}_{\max }(\mathrm{ng} / \mathrm{mL}) & 0.06(0.05) \\
\mathrm{AUC}_{0 \text {-inf }}(\mathrm{ng} / \mathrm{mL} / \mathrm{h}) & 1.19(0.84)
\end{array}
$$

a. Observed pharmacokinetic parameter values of dextrorphan of EM and IM subjects were from unpublished data. No pharmacokinetic parameter values of dextrorphan of PM subjects have been reported.

b. Mean (SD)
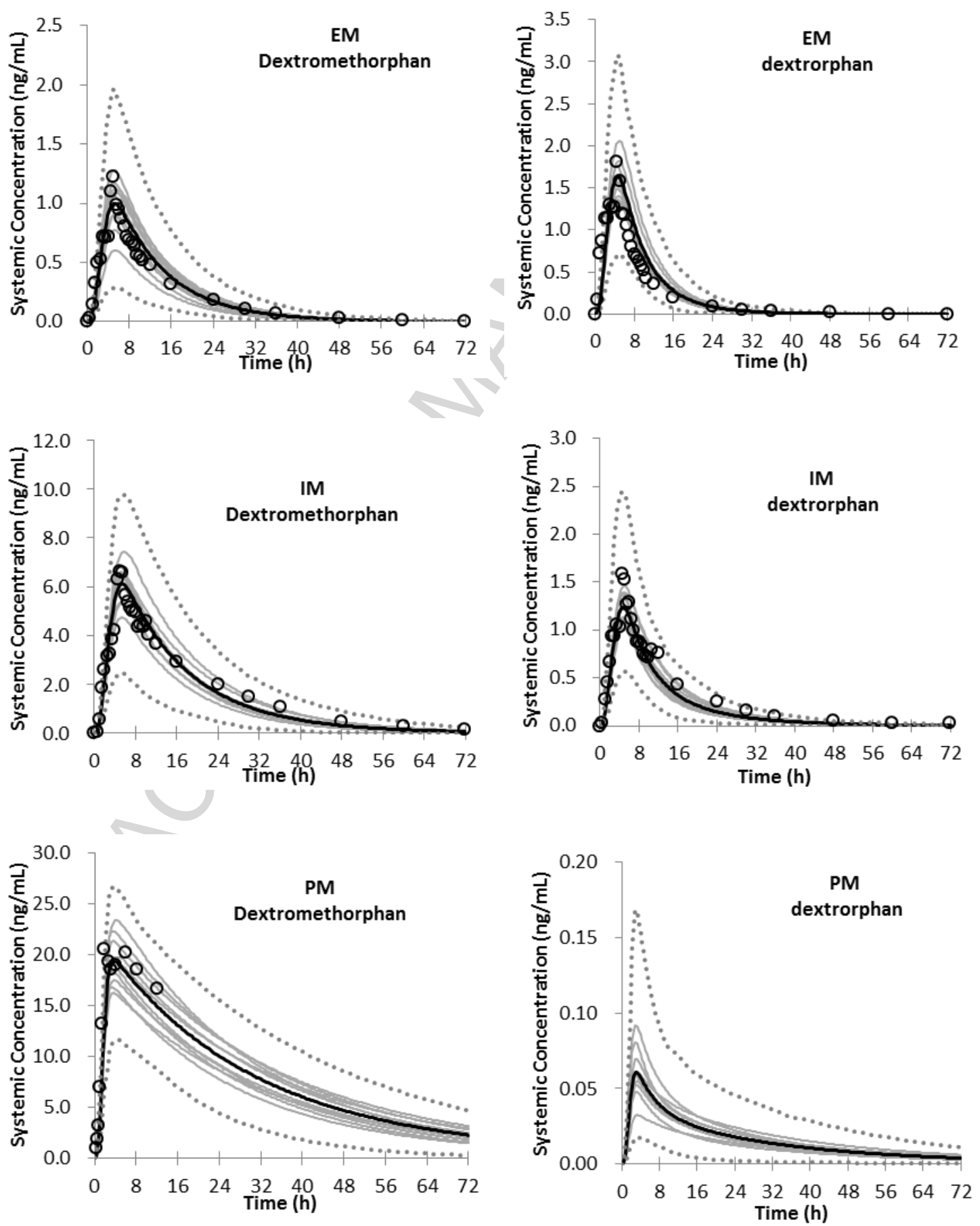

Figure 1 Simulated (lines) and observed (circles) mean plasma concentration-time curves of dextromethorphan and dextrorphan in EM, IM, and PM subjects. The gray lines represent the mean of simulations of individual trials (ten trials). The black line represents the mean 
for the total virtual population. The dashes lines represent the $5^{\text {th }}$ and $95^{\text {th }}$ percentiles for the total virtual population.

\section{Model application}

Evaluation of the phenotyping methods of CYP2D6 from single-point plasma

The corrected frequencies of EM, IM, and PM of CYP2D6 in Chinese population were $49.7 \%, 49.3 \%$, and $0.96 \%$, respectively. A virtual Chinese population of 1000 subjects consisting of $497 \mathrm{EMs}, 493 \mathrm{IMs}$, and 10 PMs were generated. The virtual population consists of 500 male and 500 female subjects, with all subjects aged 20 to 50 years.

Statistically significant correlations were found between $M R_{D M / D X}$ from $A U C_{0 \text {-inf }}$ and from single-point plasma from 1 to $30 \mathrm{~h}$ (average Spearman's correlation coefficient $=0.969$, ranging from 0.948 to 0.986 , all $p$-values $<0.001$ ) based on unpublished clinical data. Likewise, statistically significant correlations were also found between $M R_{D M} / D X$ from $A \cup C_{0 \text {-inf }}$ and from single-point plasma from 1 to $30 \mathrm{~h}$ (average Spearman's correlation coefficient $=0.949$, ranging from 0.861 to 0.997 , all p-values < 0.001) based on simulated data. Figure 2 showed the Spearman's correlation coefficients from observed data and the tendency of Spearman's correlation coefficients from simulated data. For the results from the simulated data, the Spearman's correlation coefficient increased from $1 \mathrm{~h}$, reached the maximum value (0.997) around 8 to $10 \mathrm{~h}$, and decreased thereafter to 0.861 at around $30 \mathrm{~h}$. As compared with the results from observed data, the trend from the simulated data decreased faster after reaching the maximum value. Even though the minimal value of Spearman's correlation coefficients from simulated data was smaller than that from clinical data, statistically significant correlations were still found between $M R_{D M / D X}$ from $A \cup C_{0 \text {-inf }}$ and from all single-point plasma from 1 to $30 \mathrm{~h}$ based on simulated data (Figure 2). Fourteen plasma points from 1 to $30 \mathrm{~h}$ after drug administration based on simulated data were taken as examples to show the 
correlations between $A U C M R_{D M / D X}$ and single-point plasma $M R_{D M / D X}$ in the double logarithmic coordinates (Figure 3). This result validated and extended the result from clinical data, indicating that single-point plasma from 1 to $30 \mathrm{~h}$ after a single oral dose of $30 \mathrm{mg}$ CR DM could be used as phenotyping method for EM, IM, and PM subjects.

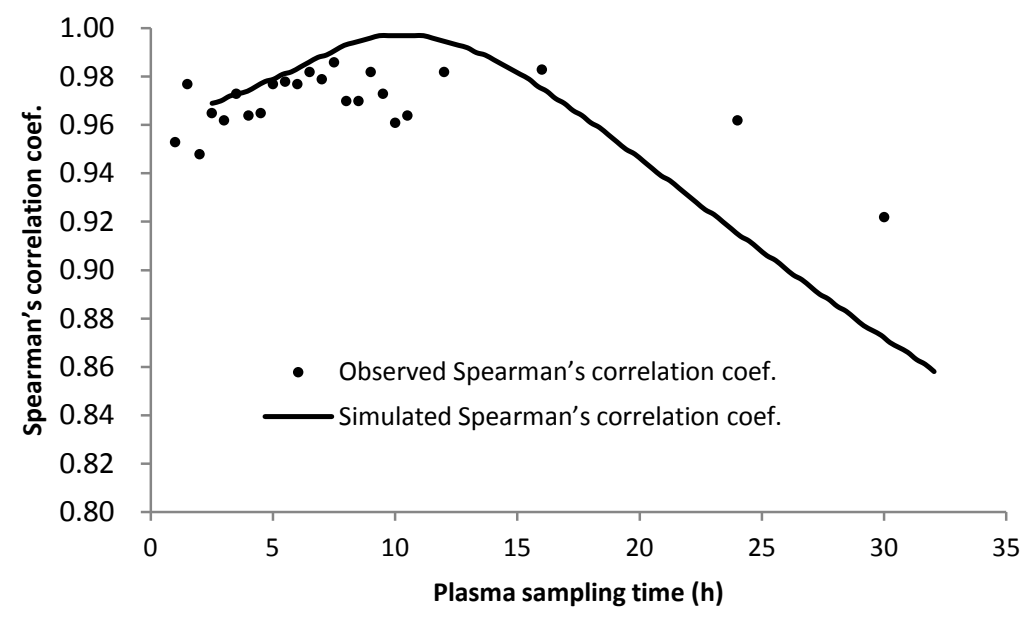

Figure 2 Spearman's correlation coefficients between $A U C M R_{D M / D X}$ and single-point plasma $\mathrm{MR}_{\mathrm{DM} / \mathrm{DX}}$ Vs. sampling time. The black dots represent the Spearman's correlation coefficient based on observed data. The black line represents the Spearman's correlation coefficients based on simulated data. 

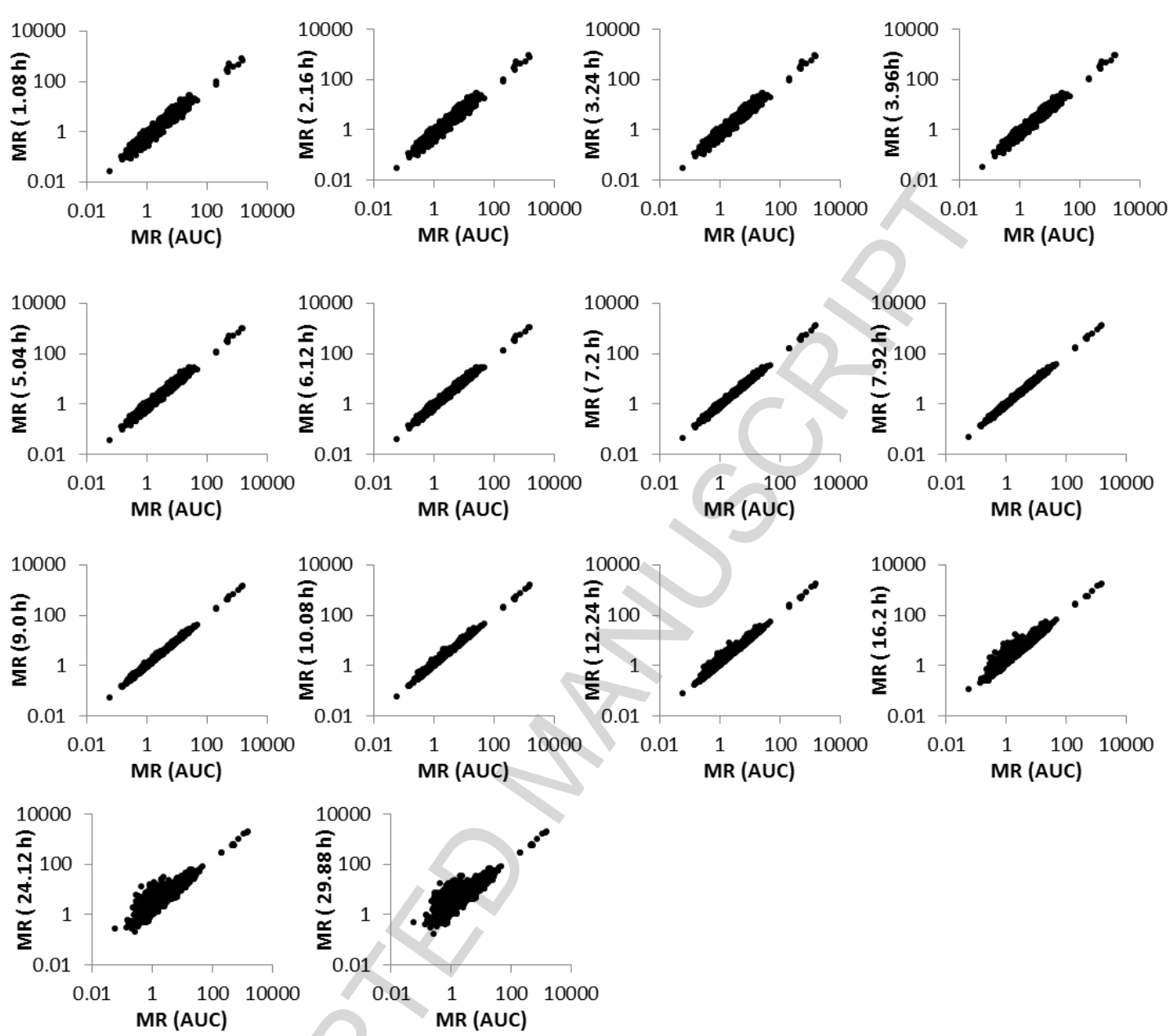

Figure 3 Correlations between $A U C M R_{D M / D x}$ and single-point plasma $M R_{D M / D X}$. Fourteen plasma points (y-axis) from 1 to $30 \mathrm{~h}$ after drug administration were taken as examples to show the correlations. The dark dots represented the simulated $\mathrm{MR}_{\mathrm{DM} / \mathrm{DX}}$ values in 1000 subjects.

\section{Discussion}

Determining $M R_{D M / D x}$ from single point plasma is potentially a good phenotyping method of CYP2D6 to reduce the required time interval and increase the reliability of data, as compared with the traditional urinary method. Clinical trials are typical and the most reliable way to evaluate the alternative phenotyping methods of CYP2D6. The limitations, however, are obvious. It is hard to do large sample size studies when multiple plasma points are targeted. Data from small sample size trials can't describe the inter-individual variability well. Given the frequencies of UM, EM, IM and PM in 
Chinese were $1.84,47.9,49.3$ and $0.96 \%$, respectively, ${ }^{[16]}$ it was unlikely to include subjects with UM or PM phenotype in a small trial in Chinese. Therefore the results from small trials could not be extrapolated to PM or UM groups.

In the present study, the PBPK models of DM and its metabolite DX in EM, IM, and PM groups were developed based on the observed data from several clinical studies in the SimCYP simulator software. No observed pharmacokinetic profiles of DM have been reported in UMs. A virtual Chinese population consisting of EM, IM, and PM subjects with the reported frequencies was developed to simulate the pharmacokinetic data in a large Chinese population. This large virtual population overcame the limitations of small clinical trials in many aspects. First, the large sample size could describe the inter-individual variability better. Large population could cover the wide range of CYP2D6 activities resulting from the allelic diversity, with lower sampling error. Second, it included EM, IM, and PM subjects in one simulated trial. It was very difficult to include the three phenotypes in one clinical study, given the small sample size and low frequencies of certain phenotypes. Actually pharmacokinetic studies in Caucasians included very few IMs and studies in Asians included no PMs so far. The large virtual population included all three phenotypes in one trial and evaluated the alternative phenotyping methods of CYP2D6 in the three phenotypes simultaneously. Therefore the analysis results from the virtual population could be applied in EM, IM, and PM subjects, as compared to that the results from the small clinical trial in Chinese could not be extrapolated to PM group. Third, large sample size could provide more reliable analysis results theoretically with lower sampling error.

The model application was evaluation of the phenotyping method of CYP2D6 from single-point plasma. The result from unpublished clinical data indicated that single-point plasma from 1 to $30 \mathrm{~h}$ after a single oral dose of $30 \mathrm{mg} C R$ DM could be used for phenotyping of CYP2D6. This result, however, couldn't be extrapolated to PM subjects. The evaluation result from simulated data demonstrated that 
single-point plasma from 1 to $30 \mathrm{~h}$ after a single oral dose of $30 \mathrm{mg} C R$ DM could be used for phenotyping of CYP2D6 in EM, IM, and PM subjects. The simulated pharmacokinetic profiles of DX in PMs showed a narrow sampling window of 3 to 16 $\mathrm{h}$ in light of the lower limit of quantification of DX being $0.025 \mathrm{ng} / \mathrm{mL}$. But another point of thought, if the sampling time is not within the narrow time window and the concentration of DX is undetectable and meanwhile the concentration of DM is quite high, then the subject is likely to be PM. Therefore the sampling window may not have to be narrowed for potential PM subjects, which is seldom seen in Chinese.

The observed concentration-time profiles of DM and DX in PM subjects were reported in very few studies and the PBPK model in PM subjects was developed only based on Capon's data. ${ }^{[7]}$ The measured concentration of DX in EMs and IMs in the unpublished study was unconjugated DX. The concentrations of DX in Capon's study were based on total DX (conjugated + unconjugated), and therefore the concentrations of unconjugated DX in PMs haven't been reported yet. The limited data in PMs may result in deviation of the simulated data. The clinical data of EMs and IMs were from 11 and 10 subjects, respectively. The mean concentration-time profiles were assumed to be the mean profiles of the Chinese population, but the mean data from a small sample might have deviations from the mean of the population. The pre-defined inter-individual variability of the virtual population was based on the coefficient of variances of all physiological parameters. The values of the coefficient of variances were based on in vitro studies or assumed, and they could be different in vivo. The cut-off values between different CYP2D6 phenotypes based on single-point plasma phenotyping method were not calculated in the present study due to the small sample size. More data with regard to different phenotyping methods of CYP2D6 as well as genotypes of CYP2D6 should be collected at the same time in large populations in the future. The rate of misclassification when using the single-point plasma phenotyping method as compared with traditional phenotyping methods of CYP2D6 (e.g., urinary phenotyping method) as well as genotypes of CYP2D6 could thus be calculated to validate this single-point 
plasma phenotyping method of CYP2D6.

\section{Conclusion}

A PBPK model of DM and its metabolite DX was developed in EM, IM, and PM subjects of CYP2D6 in Chinese population. A large virtual Chinese population consisting of EM, IM, and PM subjects with reported frequencies in Chinese was developed. $M R_{D M} / D x$ from single-point plasma from 1 to $30 \mathrm{~h}$ after administration of $30 \mathrm{mg} C R$ DM could predict the $\mathrm{MR}_{\mathrm{DM} / \mathrm{DX}}$ from AUC well and could be used as the phenotyping method of CYP2D6 for EM, IM, and PM subjects based on the simulation data.

\section{Funding}

This work was supported by Chinese National Natural Science Foundation (81503162) and a grant from the Beijing Key Laboratory (Z151100001615061).

\section{Conflict of Interest}

None declared.

\section{Acknowledge}

We acknowledge Kayode Ogungbenro for his comments. We acknowledge Amaka Ezuruike for providing the sources and references for some of the default system and drug data in SimCYP Population-based simulator ${ }^{\circledR}$, version 13.0. We gratefully thank all volunteers and working staff who have contributed to the study.

\section{Reference}

[1] Gaedigk A, Simon SD, Pearce RE, Bradford LD, Kennedy MJ, Leeder JS. The CYP2D6 activity score: translating genotype information into a qualitative measure of phenotype. Clin Pharmacol Ther. 2008;83(2):234-42.

[2] Gaedigk A. Complexities of CYP2D6 gene analysis and interpretation. Int Rev Psychiatry. 
2013;25(5):534-53.

[3] Hu OY, Tang HS, Lane HY, Chang WH, Hu TM. Novel single-point plasma or saliva dextromethorphan method for determining CYP2D6 activity. J Pharmacol Exp Ther. 1998;285(3):955-60.

[4] Chládek J, Zimová G, Beránek M, Martínková J. In-vivo indices of CYP2D6 activity: comparison of dextromethorphan metabolic ratios in 4-h urine and 3-h plasma. Eur J Clin Pharmacol. 2000;56(9-10):651-7.

[5] Jamei M, Dickinson GL, Rostami-Hodjegan A. A framework for assessing inter-individual variability in pharmacokinetics using virtual human populations and integrating general knowledge of physical chemistry, biology, anatomy, physiology and genetics: $A$ tale of 'bottom-up' vs 'top-down' recognition of covariates. Drug Metab Pharmacokinet. 2009;24(1):53-75.

[6] Moghadamnia AA, Rostami-Hodjegan A, Abdul-Manap R, Wright CE, Morice AH, Tucker GT. Physiologically based modelling of inhibition of metabolism and assessment of the relative potency of drug and metabolite: dextromethorphan vs. dextrorphan using quinidine inhibition. Br J Clin Pharmacol. 2003;56:57-67.

[7] Capon DA, Bochner F, Kerry N, Mikus G, Danz C, Somogyi AA. The influence of CYP2D6 polymorphism and quinidine on the disposition and antitussive effect of dextromethorphan in humans. Clin Pharmacol Ther. 1996;60(3):295-307.

[8] Gertz, M, Houston, JB, Galetin A. Physiologically based pharmacokinetic modeling of intestinal first-pass metabolism of CYP3A substrates with high intestinal extraction. Drug Metab. Dispos. 2011, 39, 1633-1642.

[9] Guest, EJ, Aarons, L, Houston, JB, Rostami-Hodjegan A, Galetin A. Critique of the two-fold measure of prediction success for ratios: application for the assessment of drug-drug interactions. Drug Metab. Dispos, 2011, 39, 170-173.

[10] Wang YH. Confidence assessment of the Simcyp time-based approach and a static mathematical model in predicting clinical drug-drug interactions for mechanism-based CYP3A inhibitors. Drug Metab Dispos, 2010, 38, 1094-1104.

[11] Gorski JC, Huang SM, Pinto A, Hamman MA, Hilligoss JK, Zaheer NA, Desai M, Miller M, Hall SD. The effect of echinacea (Echinacea purpurea root) on cytochrome P450 activity in vivo. Clin Pharmacol Ther. 2004;75(1):89-100.

[12] Albers GW, Atkinson RP, Kelley RE and Rosenbaum DM. Safety, tolerability, and pharmacokinetics of the N-methyl-D-aspartate antagonist dextrorphan in patients with acute stroke. Dextrorphan Study Group. Stroke, 1995, 26:254-258.

[13] Ke AB, Nallani SC, Zhao P, Rostami-Hodjegan A, Isoherranen N, Unadkat JD. A physiologically based pharmacokinetic model to predict disposition of CYP2D6 and CYP1A2 metabolized drugs in pregnant women. Drug Metab Dispos. 2013;41(4):801-13.

[14] Lutz JD and Isoherranen N. Prediction of relative in vivo metabolite exposure from in vitro data using two model drugs: dextromethorphan and omeprazole. Drug Metab Dispos. 2011; 40(1):159-168.

[15] Wagner C, Pan Y, Hsu V, Grillo JA, Zhang L, Reynolds KS, Sinha V, Zhao P. Predicting the effect of cytochrome P450 inhibitors on substrate drugs: analysis of physiologically based pharmacokinetic modeling submissions to the US Food and Drug Administration. Clin Pharmacokinet. 2015;54(1):117-27. 
[16] Qian JC, Xu XM, Hu GX, Dai DP, Xu RA, Hu LM, Li FH, Zhang XH, Yang JF, Cai JP. Genetic variations of human CYP2D6 in the Chinese Han population. Pharmacogenomics. 2013;14(14):1731-43.

[17] Abdul Manap R, Wright CE, Gregory A, Rostami-Hodjegan A, Meller ST, Kelm GR, Lennard MS, Tucker GT, Morice AH. The antitussive effect of dextromethorphan in relation to CYP2D6 activity. Br J Clin Pharmacol. 1999;48(3):382-7.

[18] Abduljalil K, Frank D, Gaedigk A, Klaassen T, Tomalik-Scharte D, Jetter A, Jaehde U, Kirchheiner J, Fuhr U. Assessment of activity levels for CYP2D6*1, CYP2D6*2, and CYP2D6*41 genes by population pharmacokinetics of dextromethorphan. Clin Pharmacol Ther. 2010;88(5):643-51.

[19] Kirchheiner J, Nickchen K, Bauer M, Wong ML, Licinio J, Roots I et al. Pharmacogenetics of antidepressants and antipsychotics: the contribution of allelic variations to the phenotype of drug response. Mol Psychiatry 2004; 9: 442-473.

[20] Zhou SF. Polymorphism of human cytochrome P450 2D6 and its clinical significance: Part I . Clinical Pharmacokinetics , 2009a, 48: 689- 723.

[21] Zhou SF. Polymorphism of human cytochrome P450 2D6 and its clinical significance: part II . Clinical Pharmacokinetics, 2009b, 48: 761 - 804.

[22] Frank D, Jaehde U, Fuhr U. Evaluation of probe drugs and pharmacokinetic metrics for CYP2D6 phenotyping. Eur J Clin Pharmacol. 2007; 63(4):321-33.

[23] Dollery C, 1992. Therapeutics drugs, second ed. Churchill Livingstone, London.

[24] Yu A, Haining RL. Comparative contribution to dextromethorphan metabolism by cytochrome $\mathrm{P} 450$ isoforms in vitro: can dextromethorphan be used as a dual probe for both CTP2D6 and CYP3A activities? Drug Metab Dispos. 2001, 29(11):1514-1520. 
Graphical abstract

In the present study, a dynamic PBPK model was developed for DM and its active metabolite DX in three CYP2D6 phenotype groups (EM, IM, and PM). A virtual Chinese population consisting of EM, IM, and PM subjects with the reported frequencies was developed to simulate the pharmacokinetic profiles of DM and DX in a large Chinese population. Statistically significant correlations were found between $M R_{D M} / D x$ from $A U C_{0-\text { inf }}$ and $M R_{D M / D X}$ from single-point plasma from 1 to $30 \mathrm{~h}$ (all $p$-values $<0.001)$. The simulation overcame some limitations of small clinical trials and indicated that MR from single-point plasma from 1 to $30 \mathrm{~h}$ after the administration of $30 \mathrm{mg} C R$ DM could predict the MR from AUC well and could be used as the phenotyping method of CYP2D6 for EM, IM, and PM subjects.
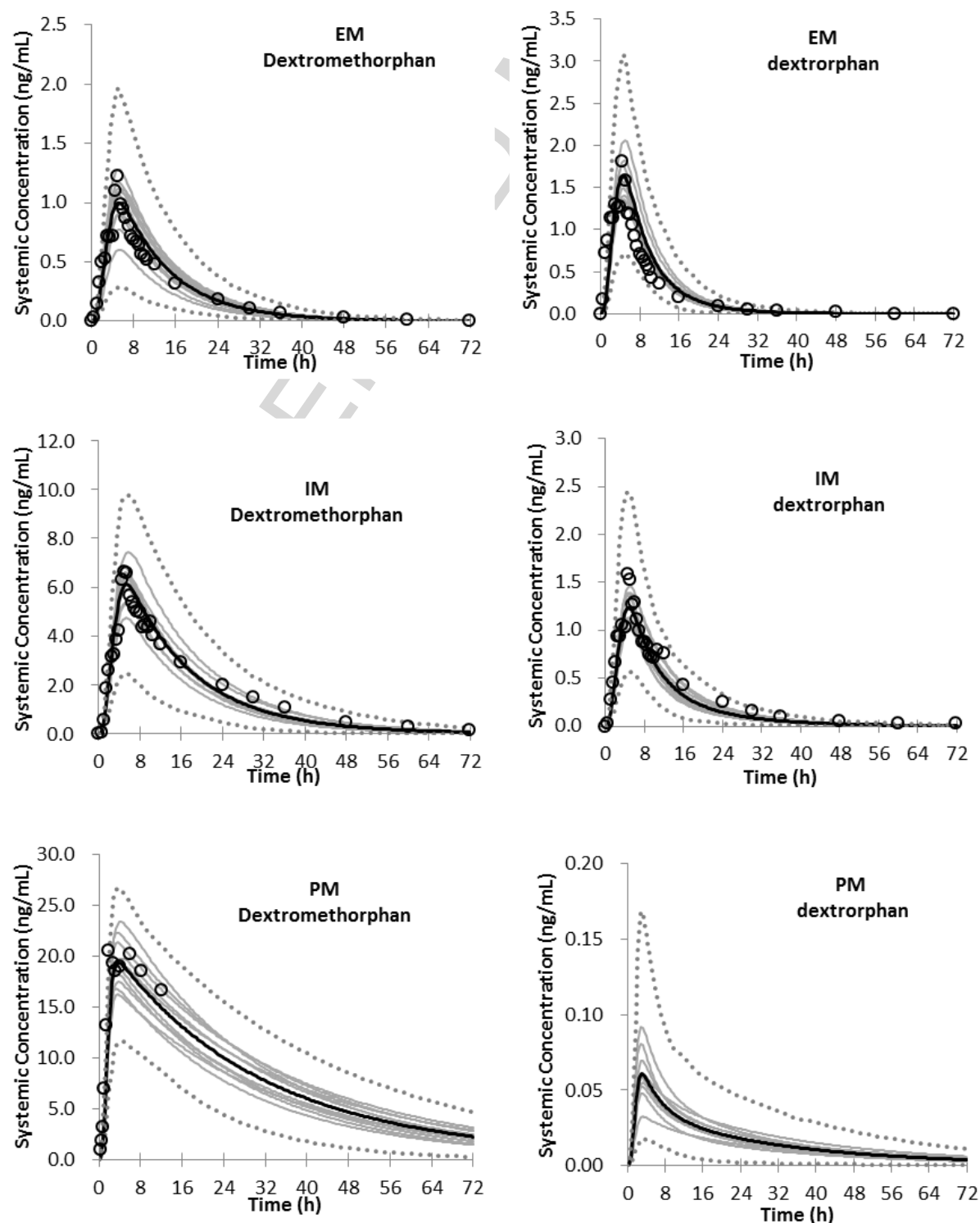

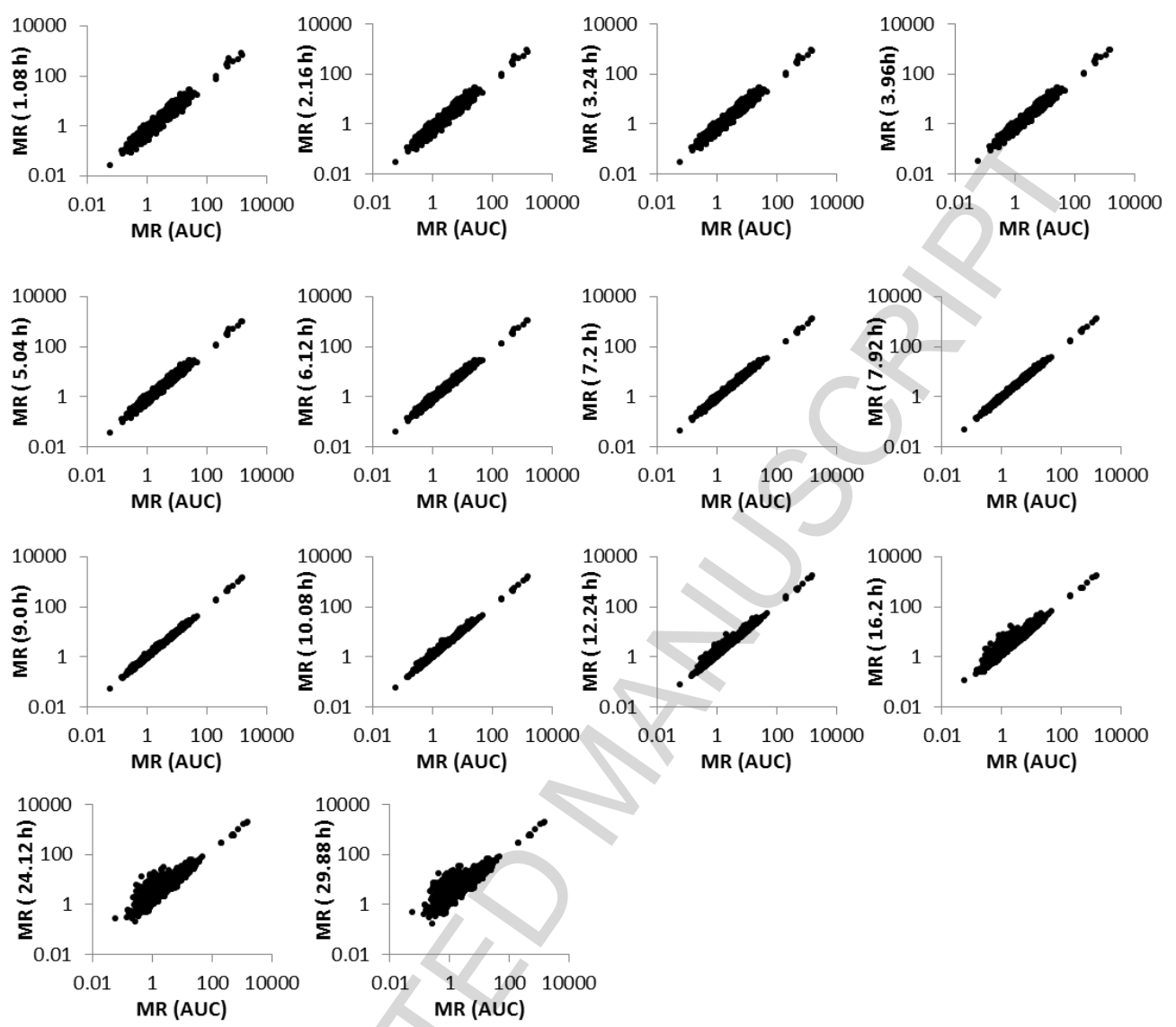